\title{
Negotiating Who Presents the Problem: Next Speaker Selection in Pediatric
} Encounters

\author{
By Tanya Stivers
}

Using audio- and videotapes of acute pediatric encounters, this study (a) identifies pediatricians' practices of next speaker selection when soliciting the problem presentation, (b) identifies factors that bear on next speaker selection, and (c) examines the consequences of physicians' selection practices for who ultimately presents the problem. Although doctors most frequently select children as problem presenters, parents are the most likely to actually present the child's problem. However, parents nonetheless orient to their children's rights to answer questions that select them as next speaker. Thus, the actual problem presenter emerges as the result of a process of interactional negotiation rather than dominance or control. This study also suggests communication resources that may increase the child's participation in presenting the problem.

When sick children visit their pediatricians, their participation in the interaction is important both in terms of the child's socialization into the role of autonomous patient and in terms of understanding the child's actual illness experience. However, children do not always communicate readily or lucidly with their doctors, and doctors must make real-time decisions about their interactions with child patients, including whether or not to ask them questions about their illness, what kinds of questions to ask, and whether to pursue particular topics with them. This paper examines one particular context of such decision making-the activity of establishing the reason for the child's visit-and explores some of the ways doctors can and do attempt to engage children in the interaction.

Two features of the pediatric encounter create interactional complications. First, the child may not be a fully competent interactant. In deciding whether to ask

\footnotetext{
Tanya Stivers (PhD, Applied Linguistics, University of California, Los Angeles) is working as a postdoctoral fellow in the Department of Pediatrics at the University of California, Los Angeles. Her research interests include language and social interaction, doctor-patient communication, and participation in multiparty contexts. The author thanks Charles Goodwin, Jeff Robinson, Emanuel Schegloff, and especially John Heritage for their comments and suggestions on earlier drafts of this paper and Health Care Partners for their assistance in video data collection for this study. A portion of this paper was presented at the 1999 annual conference of the National Communication Association, Chicago, IL.
} 
questions of children, doctors can face a dilemma: They may want to validate the child's status as a patient by asking him or her questions or providing him or her with medical advice or explanations. The child is the physician's patient and, in this sense, the owner of his or her own experience, and thus the party best equipped with the knowledge required to answer questions about and explain the medical condition (Sacks, 1984). However, children may have difficulty adequately communicating their knowledge to physicians, and it may be difficult for physicians to elicit cogent and concise answers from them. Therefore, doctors may hesitate to direct these actions to children. ${ }^{1}$

The issue of the child's competence as an interactant is compounded by the second feature-the presence of a third-party caregiver-someone who is neither physician nor patient. ${ }^{2}$ The presence of a third party has already been shown in existing literature to significantly affect the interaction (e.g., Lerner, 1993; Sacks, Schegloff, \& Jefferson, 1974; Schegloff, 1995; Simmel, 1950). In particular, in multiparty conversations, all parties are not guaranteed an opportunity to be next speaker (Sacks et al.). Moreover, a bias in turn-taking exists that favors the "just prior to current [speaker] to be [the] next [speaker]" (Sacks et al., p. 712). This bias may mean that if a doctor asks the parent a question, with this turn-taking bias it is possible for the child to be excluded from the ongoing interaction in a way that is not possible in two-party interactions (whether doctor-patient or otherwise). In the pediatric context, the parent is not only a third party but someone whom the doctor can assume to be a competent interactant. However, although the doctor can be assured of the parent's interactional competence, speaking to the parent may make it more difficult to subsequently engage the child in the interaction.

These features converge when the physician moves to ask his or her opening medical question. This question is important because it influences who will present the child's problem. Typically pediatricians move into the business of the encounter with a question such as, "Okay Robert, How can I help you today?" or, as shown below in Extract 1, "What's goin' on with Mae:.". ${ }^{3}$ With this opening question physicians may unambiguously select either the child (as the first one does) or the parent (as the second one does) to present the reason for their visit. Extract 1 shows the physician's opening question in line 1 and the mother's presentation of her child's problem across her turn in lines 3-11. This sequence constitutes the establishment of the reason for visit.

\footnotetext{
${ }^{1}$ Individual variance likely involves both linguistic ability (e.g., see Bates, Dale, \& Thal, 1995) and aspects of the child's socialization and family communication (Ochs \& Schieffelin, 1984).

${ }^{2}$ Although it is possible to have more than three participants, typically a parent, a child, and a physician are present. In the course of the interaction, the parent and child may be treated both as a single party and as two parties. When there are more than three participants, they also frequently interact as three parties. For example, when two family members accompany a child (father and mother, grandmother and mother), they orient to the interaction and are regularly treated by the physician as a single party (e.g., by copresenting the child's problem).

${ }^{3}$ For a discussion of openings, see Heath (1981) and Robinson (in press).
} 


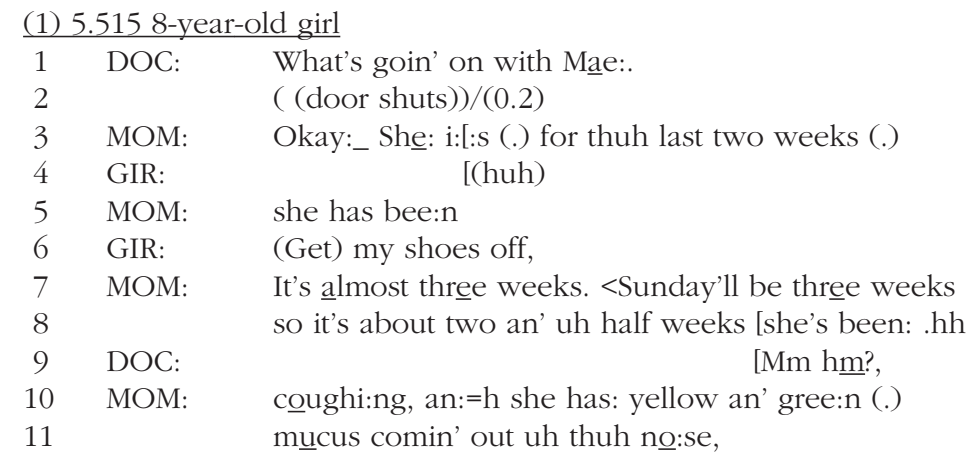

An alternative to such unambiguous next speaker selection practices is a problem solicitation that does not clearly address either the parent or child. For example, when the doctor asks, "How can I help you today." where "you" is both vocally and nonvocally unclear as to whom it is addressed, the speaker being selected is left ambiguous. In this case, it remains to be determined whether the parent or child will self-select to present the problem, and this may be negotiated between them.

Which party presents the child's problem is important for three reasons. First, this is a primary opportunity for the presenting party to express his or her concerns (Beckman \& Frankel, 1984; Korsch, Gozzi, \& Francis, 1968; Lipkin, Frankel, Beckman, Charon, \& Fein, 1995). Second, during the problem presentation the presenting party also has the opportunity to provide a more expansive explanation of their problem in narrative terms (Beach, 2001; Heritage, in press). Third, during the problem presentation, the participants define whether or not the child will be treated as an autonomous patient with rights to narrate his or her own illness experience.

Given a consensus that it is important that children participate in interactions with their pediatricians, this paper investigates three issues surrounding the physician's opening question. This paper examines (a) the practices used by pediatricians in selecting the parent or child to speak next; (b) whom the pediatricians in the sample selected and the factors that bear on this selection; and (c) the relationship between whom the pediatrician selected and who presented the child's problem.

\section{Background}

Medical textbooks generally suggest that as children become able to vocally contribute to the interaction, physicians should involve them in the medical interview (Athreya \& Silverman, 1985; Seidel, Ball, Dains, \& Benedict, 1995). Bates, Bickley, \& Hoekelman (1995) point out that "children of 5 years or older are able to add significantly to the history and can describe more accurately than can parents the severity of the symptoms and their own level of concern regarding them" (p. 21). 
Additionally, research indicates that when physicians talked more extensively with children, parents were more likely to be satisfied and more likely to adhere to recommended therapy (Freemon, Negrete, Davis, \& Korsch, 1971).

Although empirical research has shown that children regularly are treated as relevant participants in pediatric interactions, efforts to describe the extent of their participation in the medical interview are somewhat inconsistent. Some research indicates that doctors devote substantial amounts of time to interacting with their child patients. For example, in the context of routine pediatric encounters, Pantell, Stewart, Dias, Wells, \& Ross (1982) found that 33\% of all statements during the encounter were made by the doctor to the child. They further found that of the statements made by physicians to children, the highest percentages were during the physical examination (approximately 35\%), the presentation of symptoms (approximately 20\%), and social exchanges (approximately 15\%). Van Dulmen (1998) found similar results. In his data, pediatricians asked children a substantial proportion of medical questions (26\%). He further found that physicians directed 13\% of medical information to children.

However, researchers' documentations of the amount of participation with children are inconsistent across studies, whether due to methodology, context, or definitions of participation (see Tates \& Meeuwesen [2001] for a review of the literature and fuller discussion of these differences). For example, when we turn from Pantell et al. (1982) and van Dulmen (1998) to other studies, the amount of physician-child communication shown to exist is markedly decreased. Freemon et al. (1971) found that in their emergency room data, doctor-child interaction accounted for only $12.5 \%$, with only $2.1 \%$ of the total being made by the child to the doctor. Additionally, nearly $50 \%$ of doctor to child talk was described as "friendly" or social rather than medical in nature. Although this may have been in part a result of the emergency room context, Aronsson \& Rundström (1988) in their study of a Swedish allergy clinic found similar results. In their research, the child's discourse accounted for only $8 \%$ of the interaction. It also is worth noting here that, whereas van Dulmen (1998) found that doctors spent significant amounts of time talking to children, he found that only $4 \%$ of doctor-child interaction was from the child. Thus, on the one hand, that children are communicated with at all during these encounters supports a general claim that children are treated as participants and further that they in fact contribute to their medical interactions. On the other hand, however, despite being the patient and thus the reason for and focus of the medical interview, their communication comprises a relatively small proportion of the interactions.

Other research on pediatrician-parent-child interaction suggests that with both a child patient and a parent to communicate with, physicians have additional interactional pressures placed on them (Tannen \& Wallat, 1986, 1987). Tannen \& Wallat and Worobey, O'Hair, \& O'Hair (1987) have discussed some of the resources used by physicians to help manage the sometimes conflicting demands of interacting with a child and a parent, including the use of different voice registers. Aronsson and Rundström (1988) have argued that children's contributions to the pediatric encounter are regulated by both doctors and 
parents, and that, in particular, parents frequently intervene even when a doctor's turn has been addressed to the child. They assert that a high control parent will dominate the encounter and allow their child to participate less than a low control parent who asserts his or her authority in less direct ways (1988).

In sum, there is relatively little existing research on doctor-child interaction, and what exists is somewhat difficult to interpret, particularly in terms of the child's participation in the interaction. Though Pantell et al. (1982) examined doctors' statements in terms of the activity context in which they occurred (e.g., during the presentation of symptoms or during the physical examination), other researchers have looked at participation across the whole of the interaction. This, along with different units of measurement and different medical contexts, may account for the disparity in results in the current communication research. In this paper I will focus on a single activity-establishing the reason for the visit- to examine the organization of participation. I will argue that the child's participation in this activity is primarily the result of a combination of the pediatrician's selection of next speaker and the parent-child negotiation of who will present the child's problem. In exploring this theme, I will look first at pediatricians' practices for selecting next speaker, provide a distributional breakdown of those practices and relate them to outcomes, and then examine instances of negotiations after the pediatrician addressed a solicitation to the child.

\section{Data and Method}

The data are drawn from a corpus of 291 acute pediatric encounters recorded in Southern California during 1995-1996. Fifty of these visits were videorecorded, and 241 were audiorecorded. ${ }^{4}$ The initial analysis of practices related to selecting the next speaker was done using video data. Within the video corpus, all usable data were included in the sample, yielding a total of 26 encounters. Usability was defined as a visit that included a solicitation of the reason for the visit by the doctor. Most of the time doctors initiate a move to business with an inquiry about the reason for the visit, but in these data approximately $30 \%$ of the time doctors do not solicit a problem presentation from the parent or child at all. There are two primary accounts for this: First, in cases where the parent or child has presented the problem "early" (i.e., prior to the physician's solicitation), doctors will not solicit a presentation of the problem. For example, in response to "How are you?" the parent or child might preemptively explain the child's illness (Robinson, 1998). Second, a doctor may initiate business with a history-taking question (e.g., "Okay: so she's had this raspy cough for about five day:s?"). ${ }^{5}$ Although these questions

\footnotetext{
${ }^{4}$ I would like to thank Dr. Rita Mangione-Smith who allowed me access to her audiotaped corpus of data. For the purposes of this paper I have drawn on both this database and a corpus of videotaped encounters that I collected.

5 This contrasts with the data corpus discussed by Robinson (1998). It appears that there may be individual variation in the practices physicians use to move into the business of the medical encounter.
} 
frequently select a next speaker, because they are history-taking questions and not problem solicitations, I have not included them for discussion here. ${ }^{6}$

Within the audio corpus, cases were randomly selected for possible inclusion in the sample. The same usability criteria were applied until a total of 74 cases were found, in order to yield a total of 100 encounters. The sample involves 13 physicians in both community- and university-based practices. ${ }^{7}$ Because of the presence of two children in some encounters, a total of 102 problem solicitations are discussed.

This study uses conversation analysis (CA) to identify and analyze doctor-parent-child interactions within the "establishment of the reason for the visit" context (for a review of CA, see Drew \& Heritage, 1992; Heritage, 1984). This methodology relies on the recording of naturally occurring interaction and the careful transcription of these events to study recurrent patterns within the interaction. Statistical methods are also used in order to examine the relationships between interactional processes and outcomes.

\section{Analysis}

\section{Practices Pediatricians Use for Selecting Next Speaker}

Doctors' problem solicitations are generally designed as requests for information. In the design of these requests, they regularly, though not necessarily, select a specific recipient to respond. According to Sacks et al. (1974), turns may or may not select a particular next speaker. Although asking a question makes answering relevant in the next turn, the action of asking does not in itself allocate that turn to a next speaker (Sacks et al.; Schegloff \& Sacks, 1973). For example, the use of "you" may, as Lerner points out, indicate that a single recipient is being addressed "without designating specifically who is being referred to" (in press, p. 12). In such cases, selection of a next speaker requires the use of additional practices. For example, gaze in multiparty interaction can disambiguate a turn that is addressed with the second person pronoun "you." Lerner has also differentiated "explicit" and "tacit" practices for next speaker selection (Lerner, in press). He asserts that "when the requirements for responding to a sequence-initiating action limit eligible responders to a single participant, then that participant has been tacitly selected as next speaker" (in press, p. 11). When a question does not specifically select the next speaker, responses will be the result of self-selection. It is also the

\footnotetext{
${ }^{6}$ In cases where there is no problem solicitation, the participation of the child may be further diminished. In these data, most of the initial history-taking questions select the parent (e.g., "How long has she been sick?"). Given that over $20 \%$ of doctor-child interaction is contained in the presentation of symptoms activity context (Pantell et al., 1982), if this activity is absent, the amount of doctor-child interaction will be decreased.

7 In this context, as opposed to urgent or emergency contexts, the illnesses are typically mild. This may further affect who is selected to present the problem and who presents the problem because in a situation where the child is more seriously ill or is thought to be seriously ill selection practices might be expected to differ.
} 
case that in a party of two or more interactants, self-selection may occur within the party (Sacks et al.).

\section{When Doctors Unambiguously Select a Next Speaker}

In these data, pediatricians routinely select the next speaker. For example, returning to Extract 1 the doctor selects the mother to provide an explanation of her daughter's problem.

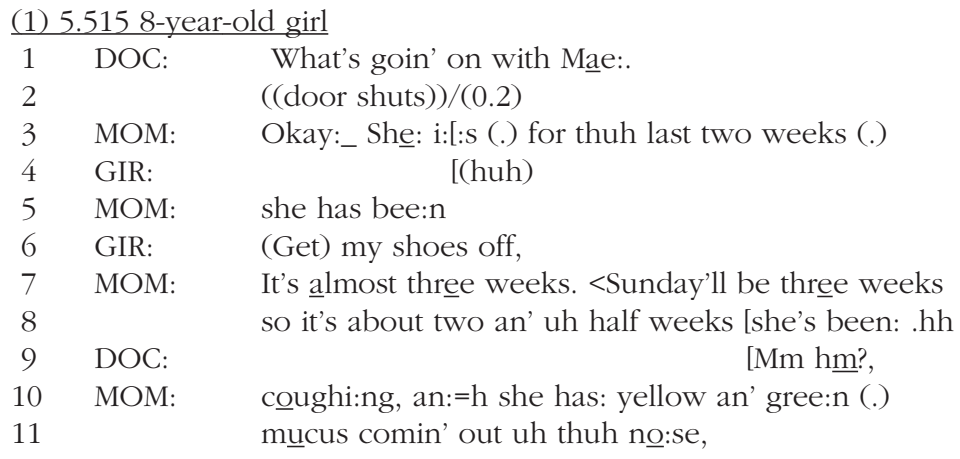

In line 1 the doctor solicits a problem presentation with an open-formatted request for information. She selects the mother to respond to her query by referring to the girl in the third person-as someone being talked about rather than someone being talked to (line 1). As the mother is the only party who can talk about "Mae," this question tacitly selects the mother as next speaker (Lerner, in press). The mother, beginning in line 3, responds by presenting her daughter's problem as ongoing coughing and nasal discharge.

Similarly, in Extract 2, the doctor selects the parent to respond to a request for confirmation that her five-year-old daughter is ill.

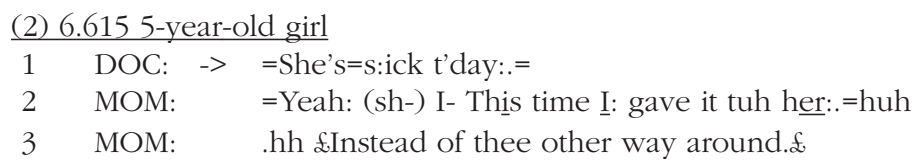

The problem solicitation in line 1 is formatted as a "B-event" statement (Labov \& Fanshel, 1977). Specifically, the doctor's comment is about a fact that is known by the mother and child first and foremost. B-event statements are routinely treated by interactants as seeking confirmation (Labov \& Fanshel). Additionally, the statement is vague and in need of elaboration, and the mother here treats this as both a request for confirmation and as seeking elaboration. The problem solicitation, like the one in Extract 1, selects the mother through the practice of tacit selection. Here, it is not the girl's name but the pronominal reference to her that places the mother as the only eligible recipient.

By contrast, in Extract 3, the doctor solicits the problem presentation from the girl. 


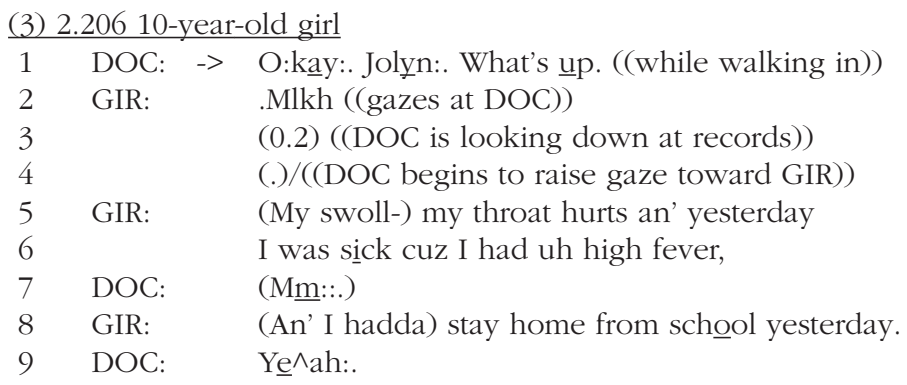

The doctor selects the girl as next speaker by asking a question that is addressed to her (in line 1 with "Jolyn:"). The girl orients to having been selected as next speaker by looking toward the doctor and beginning to respond (line 2). However, the doctor is not gazing toward her. After 0.2 seconds the doctor begins to raise her gaze toward the girl displaying her readiness for a response (Goodwin, 1981), and with this the girl begins her problem presentation. Across this sequence each of the participants displays an orientation to the child as having been selected as next speaker. The doctor and girl are oriented bodily toward each other. The girl gazes toward the doctor throughout the sequence and displays a readiness to respond (line 2 ) and then ultimately does respond (lines 5-6/8). The mother does not alter her body position throughout. She keeps her lips closed and, although gazing toward the doctor and child, she displays no orientation to responding to the doctor's query.

Similarly, in the next case the physician's problem solicitation (line 7) selects the boy as next speaker by virtue of the earlier address term (line 5).

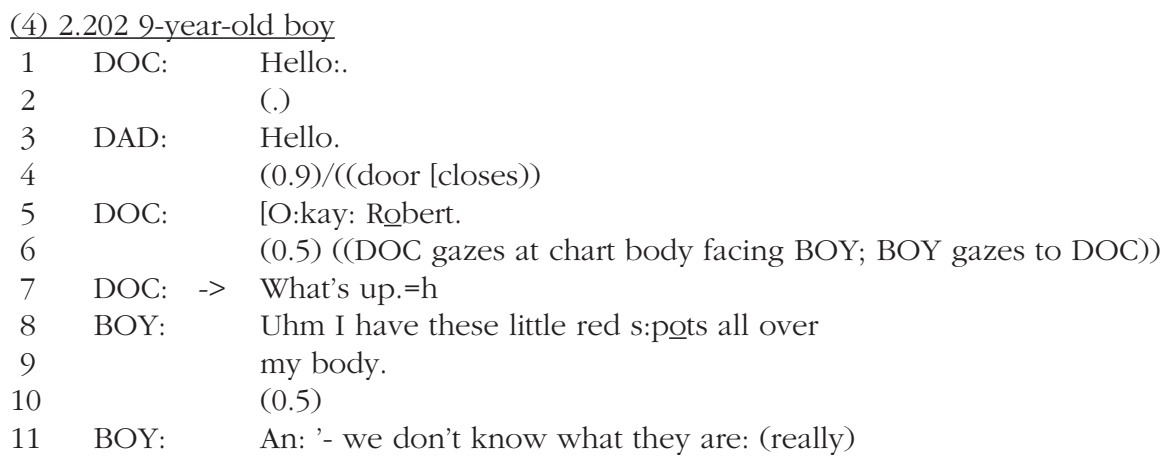

In line 5 the "O:kay:" appears to display the doctor's shift in orientation from the earlier greeting sequence (Beach, 1995). The use of the address term "Robert." appears to display her orientation to the boy as a patient and to him as "business at hand." When she then, after 0.5 seconds of silence, solicits the boy's problem, this hearably selects the boy as next speaker. Her body orientation is facing the boy with most of her back toward the father, and the boy is gazing at her. The boy promptly, in lines 8-11, presents his problem, offering his primary symptom ("little 
red s:pots") and indicating his search for a diagnosis of the symptom (line 11). In this way he, too, displays his orientation as the party who was selected as next speaker.

Doctors can select even very young children to present their problems. In the following case with a girl of only $21 / 2$ years, the doctor selects the child.

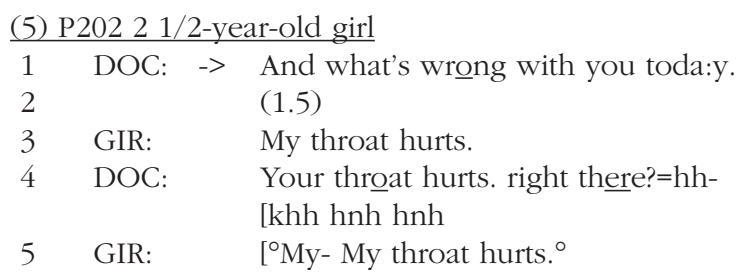

Here, the doctor selects the girl through his use of the second person pronoun "you". As the participant who is ill, she tacitly is selected as the only eligible "you" who has something "wrong". Although there is an initial delay, she answers the question in line 3 without further vocal pursuit by either the doctor or the parent. In responding the girl displays her understanding that the question in fact selected her to respond.

\section{When Doctors Are Ambiguous in Selecting a Next Speaker}

In these data, pediatricians most often unambiguously select a next speaker to present the child's problem. However, at times doctors are ambiguous in their selection of a next speaker. When this is the case, the determination of who will present the problem remains to be made. This practice can result in a problem presentation by either the parent or the child or a problem presentation that is the product of collaboration between the parent and child. Often, this is managed through a process of interactional negotiation. In the following case, the doctor turns toward the sink as he solicits the problem. Ultimately the child presents her problem.

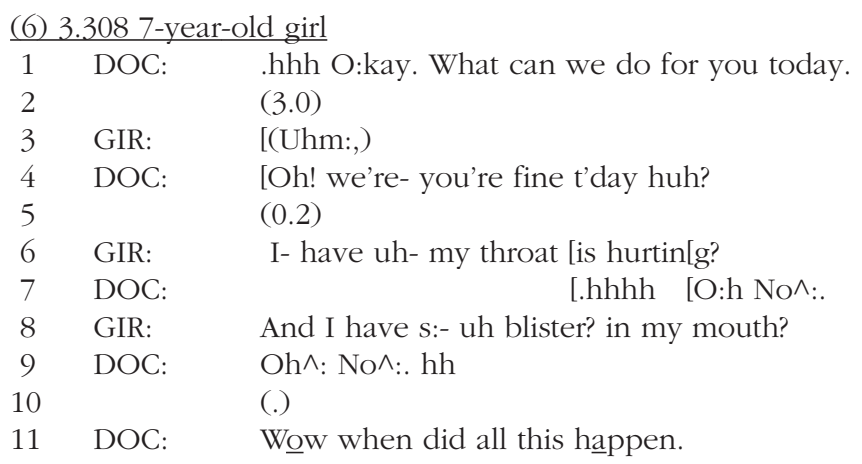

As mentioned, the doctor solicits the problem as he turns away to wash his hands. This is shown in figure 1. The doctor's choice of "you" as an address term in this case leaves it ambiguous as to whether he is selecting the mother or daugh- 


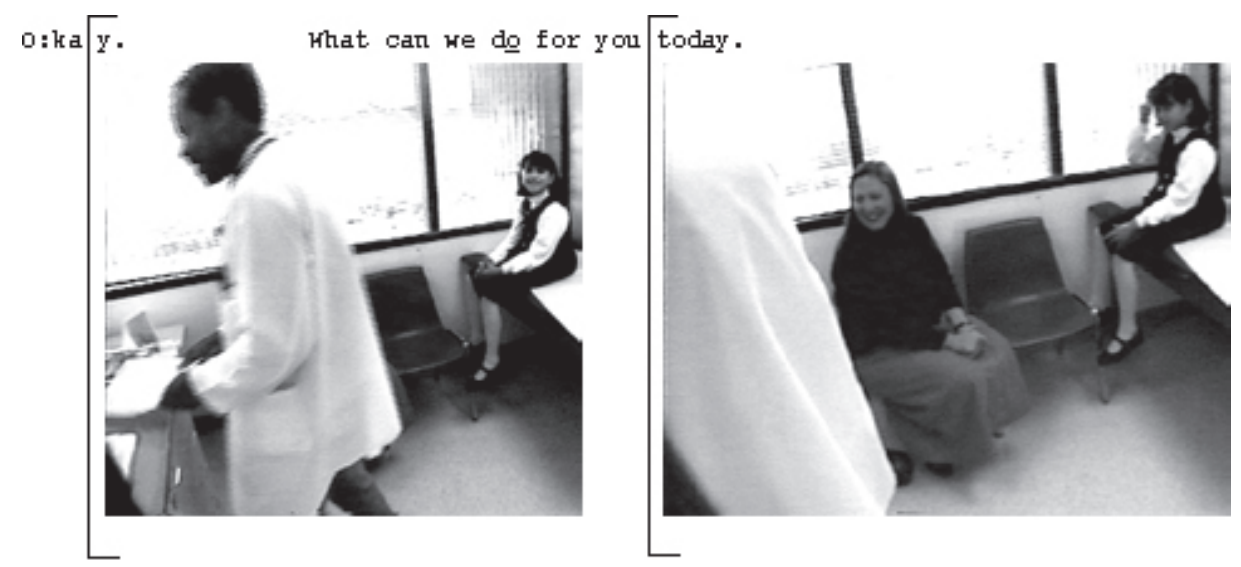

Figure 1. Extract 6, line 1.

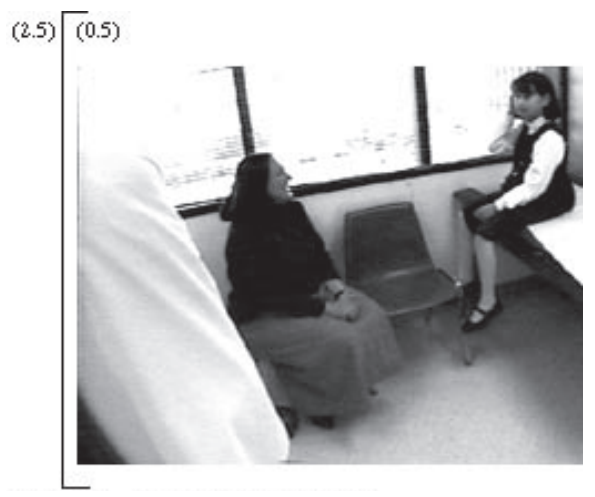

Figure 2. Extract 6 , line 2.

ter because, in contrast to the earlier case where only the child is eligible to speak to something being "wrong", in this case, both the child and the mother are eligible recipients to a query about what the physician can do for them. Thus, the decision of who will respond is left to the mother and daughter to work through. Upon completion of the doctor's turn at line 1 the doctor is facing the sink, and the mother's gaze is toward his hands, as is her daughter's. After 1.1 seconds of silence, the mother begins to turn her gaze toward her daughter, reaching her-as shown in figure 2-after 2.5 seconds. The mother's gaze displays an orientation to her daughter as the participant who should respond.

The girl continues to gaze toward the doctor across this silence until, in overlap at line 3, she begins with "Uhm:,". After the completion of the doctor's teasing remark at line 4, the girl presents her problem in lines 6 and 8. The doctor's teasing remark pursues a response from the girl. However, this does not occur until after the mother and daughter have gone through an initial nonvocal interaction in which the mother has oriented to her daughter as the appropriate next 
speaker and after the daughter has collaborated with this and begun a response (line 3).

Thus, the initial solicitation of the problem involves a negotiated process of selection. The negotiation can be seen, in this case, to take the form of the mother's shifting her gaze to the child, thus holding her daughter accountable for answering the question and displaying her orientation to the relevance of the child's answering the question (e.g., the mother does not gaze toward the doctor, does not take an inbreath, nor does she shift her posture but rather holds her gaze and posture toward her daughter).

In this case we have seen that it is possible for a parent to treat a child as responsible for presenting the problem by gazing toward her and withholding an answer to the doctor's question. It is relatively common for parents to hold their children accountable either vocally (see Extract 10, below) or nonvocally (as seen in Extract 6) when children have been selected as next speakers but are not readily responding to the doctor's solicitation. However, typically, when a doctor does not select a next speaker, it is the parent who presents the problem. This might be interpreted as children simply being excluded from the participation structure if they are not selected, but this is not necessarily the case. The process of self-selection is often one of negotiation between the parent and child, as we saw in Extract 6. In Extract 7 the doctor again is ambiguous in his selection of a next speaker and leaves it to the parent and child to negotiate. Although it is the parent who ultimately presents the problem, this is, again, only after negotiation with the child.

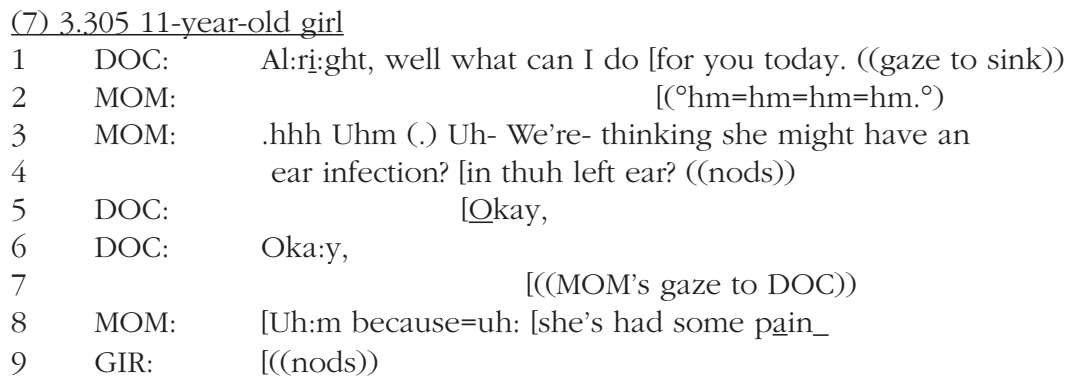

After the doctor's problem solicitation (line 1), the mother turns her gaze to her daughter as she takes an inbreath in line 3 (Figure 3).

At the beginning of "Uhm" the daughter brings her gaze to the mother and they share mutual gaze through "Uh-" (Figure 4), at which point the mother brings her gaze to the doctor as she begins the problem presentation. The mother returns her gaze to the daughter at the beginning of line 6. In response the daughter nods, confirming the presentation of the problem (line 9). In responding to the doctor's solicitation of the problem the mother and daughter negotiate-both vocally and nonvocally-who will present the problem. The mother's gaze toward the daughter in line 3 and the delays and hitches with which she ultimately begins her turn (".hhh Uhm (.) Uh- We're-") display her orientation to some negotiation of who 


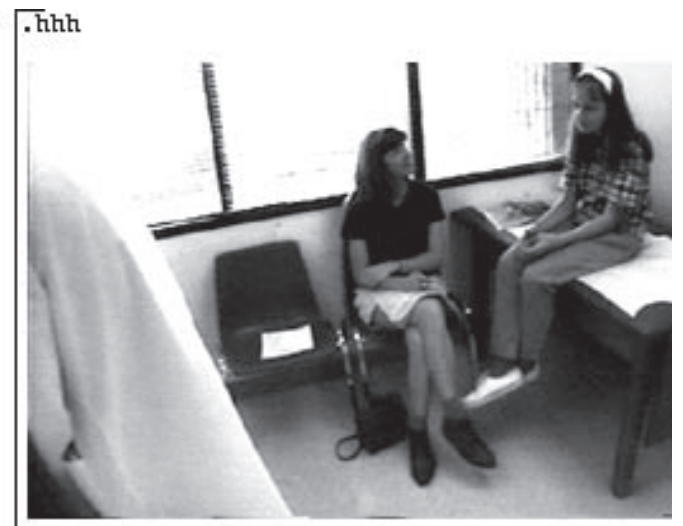

Figure 3. Extract 7, line 3.

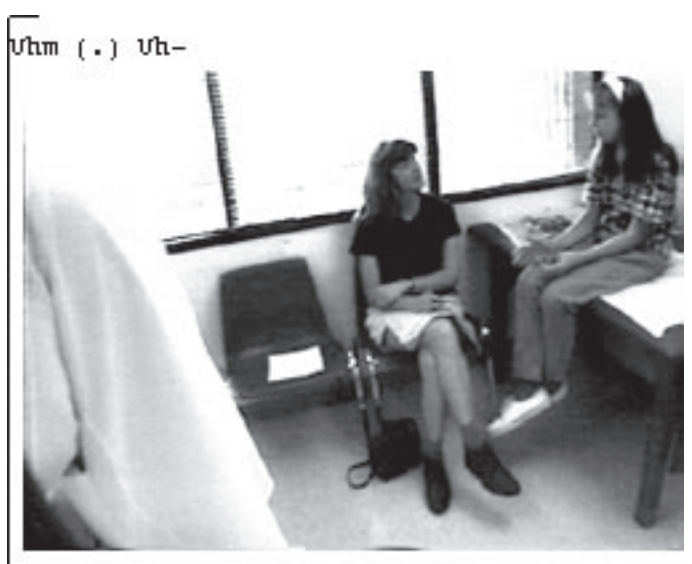

Figure 4. Extract 7, line 3.

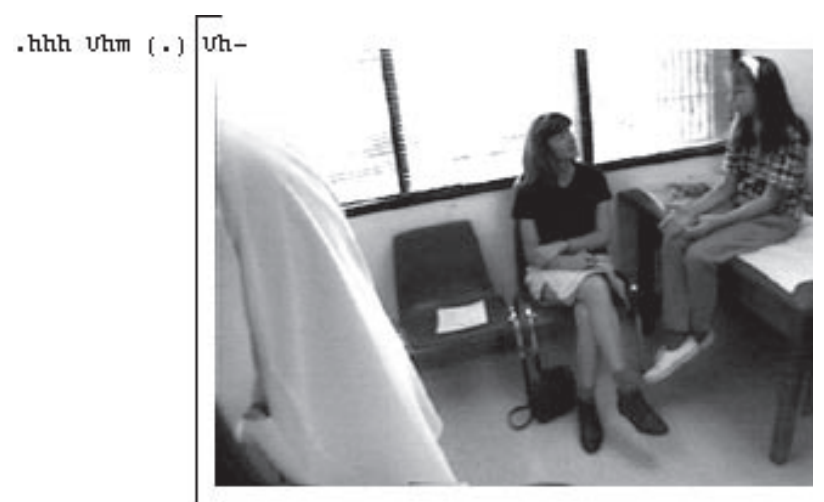

Figure 5. Extract 7, line 3. 
will answer the doctor's query. The daughter also orients to this as she brings her gaze to the mother in line 3 and perhaps further in overlap with the mother's "Uh-" where the daughter gestures toward the mother with an open palm-a gesture that may serve to hand over the floor (see Figure 5).

However, throughout this negotiation of participation the mother displays her preparedness, and perhaps further her ultimate responsibility, for answering this question if her daughter does not. That is, she does not remain silent as the mother in Extract 6 did, but rather she utilizes increasingly strong turn-holding practices-first the inbreath, then "uhm," and finally a cut off "uh-" (Schegloff, 1996) to maintain rights to the floor.

Negotiation of who presents the problem also can occur among adult caregivers during pediatric encounters. When multiple caregivers are present and neither is selected as next speaker, the same issues of negotiation apply. For example, in Extract 8 the boy has been accompanied by both his father and his paternal grandmother. Both are caregivers for the child and at different points in the encounter display knowledge about the child's illness. When the pediatrician solicits the problem she does this by selecting the father and grandmother as a partycaregivers-by asking for information about the boy rather than of the boy. Following this solicitation, there is some deliberation as to who will present the problem.

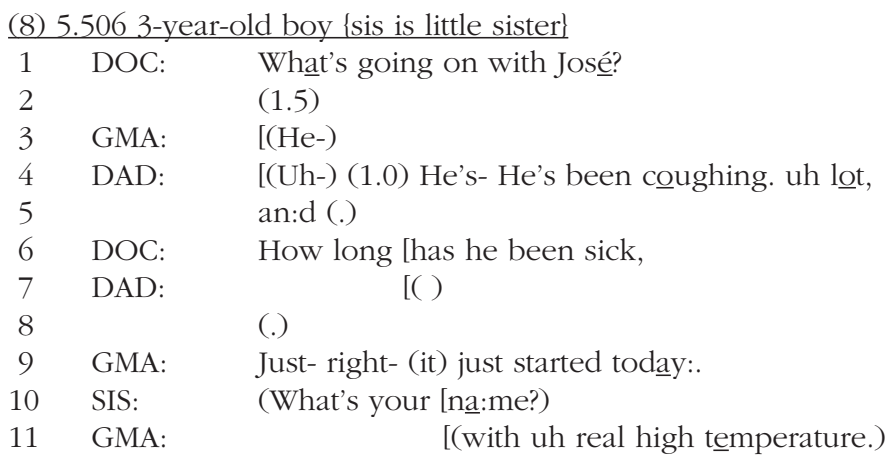

Here the doctor solicits the problem in line 1 as she walks between the two adult participants gazing down and walking toward the opposite wall of the room. As can be seen in Figure 6, none of the participants share mutual gaze. During the silence at line 2 the grandmother sits on the bench, and the father follows his son in order to pick him up.

After 1.5 seconds the grandmother and the father begin simultaneously (lines 3-4), yet upon discovering themselves to be in overlap both quickly cut off their turn beginnings. ${ }^{8}$ These features of the talk argue for an orientation on the part of both the grandmother and the father toward the necessity for one of them to produce an answer to the doctor's question. However, neither appears prepared to override the other when they hear that they are simultaneously producing an

${ }^{8}$ For a discussion of this practice, see Schegloff, 2000. 


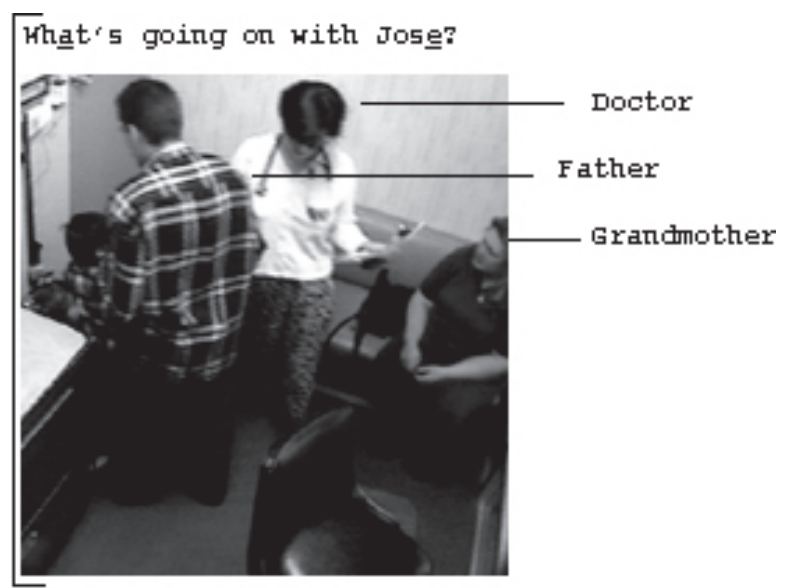

Figure 6. Extract 8 , line 1.

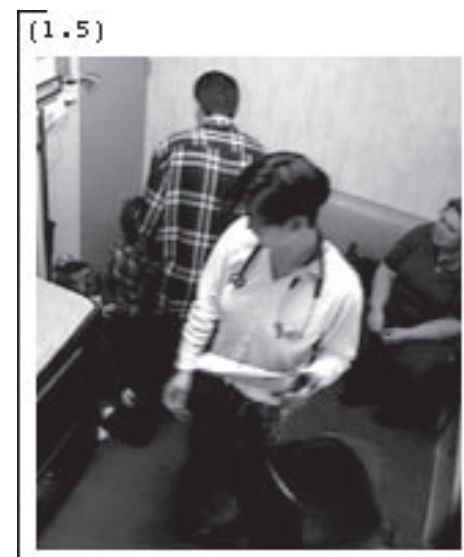

Figure 7. Extract 8, line 2.

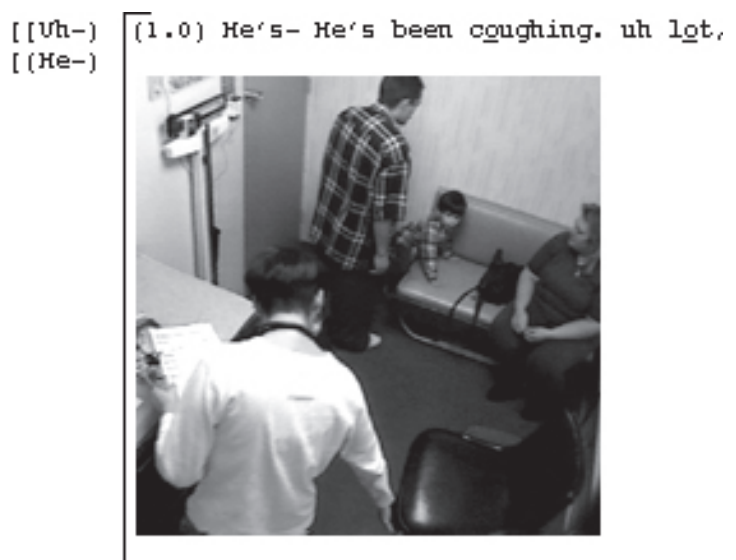

Figure 8. Extract 8, lines 3-4. 


\begin{tabular}{lccc}
\hline \multicolumn{2}{l}{ Table 1. Frequency } & Distribution of Physician's Next Speaker Selection & \\
Doctor selects & Frequency & Percentage & Cumulative \\
\hline Parent & 30 & 29.41 & 29.41 \\
Child & 54 & 52.94 & 82.35 \\
Ambiguous & 18 & 17.65 & 100.00 \\
Total & 102 & & \\
\hline
\end{tabular}

answer. Following this, there is a second silence of 1.0 second during which, again, there is no mutual gaze among the participants (see figure 8).

After this time the father presents the problem. Here, when the doctor asks her first history-taking question the father turns his gaze upward displaying a thinking posture (Goodwin \& Goodwin, 1986); however within a micropause the grandmother answers the question. In this way both the father and the grandmother establish, within a short space of time, that they are both knowledgeable about the boy's condition.

We have seen in these examples that doctors can select either parents or children as next speakers or they may be ambiguous in their selection of a next speaker. When the doctor's next speaker selection is ambiguous, the negotiation of who presents the problem largely rests on the other participants. We now turn to our second point of inquiry: to describe the distribution of whom pediatricians select as next speaker and the factors that may affect this selection.

\section{Next Speaker Selection: Distributions and Explanatory Variables}

The qualitative analysis of these data provides information on the processes of speaker selection. A statistical analysis of these data permits an analysis of the statistical relationships between the interactional processes being examined and the outcomes. To establish the frequency with which doctors selected parents or children to present the reason for the visit, each of the 102 problem solicits were coded for whom the doctor selected with his or her question. The results are presented in Table 1, which shows that most of the time (53\%) doctors selected children to present the problem. Parents also were selected to present their children's problems a substantial percentage of the time (29\%). Finally, physicians were ambiguous in their selection of a next speaker in $18 \%$ of the cases examined here.

\footnotetext{
9 Thirteen of the 18 cases here were audio only. Thus, whereas all of the video cases were both vocally and nonvocally ambiguous, some of the audio cases may involve nonvocal next speaker selection (e.g., through gaze or gesture), which would have decreased the size of this cell. However, within the video corpus, $19 \%$ of the cases were ambiguous, so $18 \%$ as a proportion of cases in the full corpus that were ambiguous is likely to be quite close to the reality if we had video for each of the cases.
} 


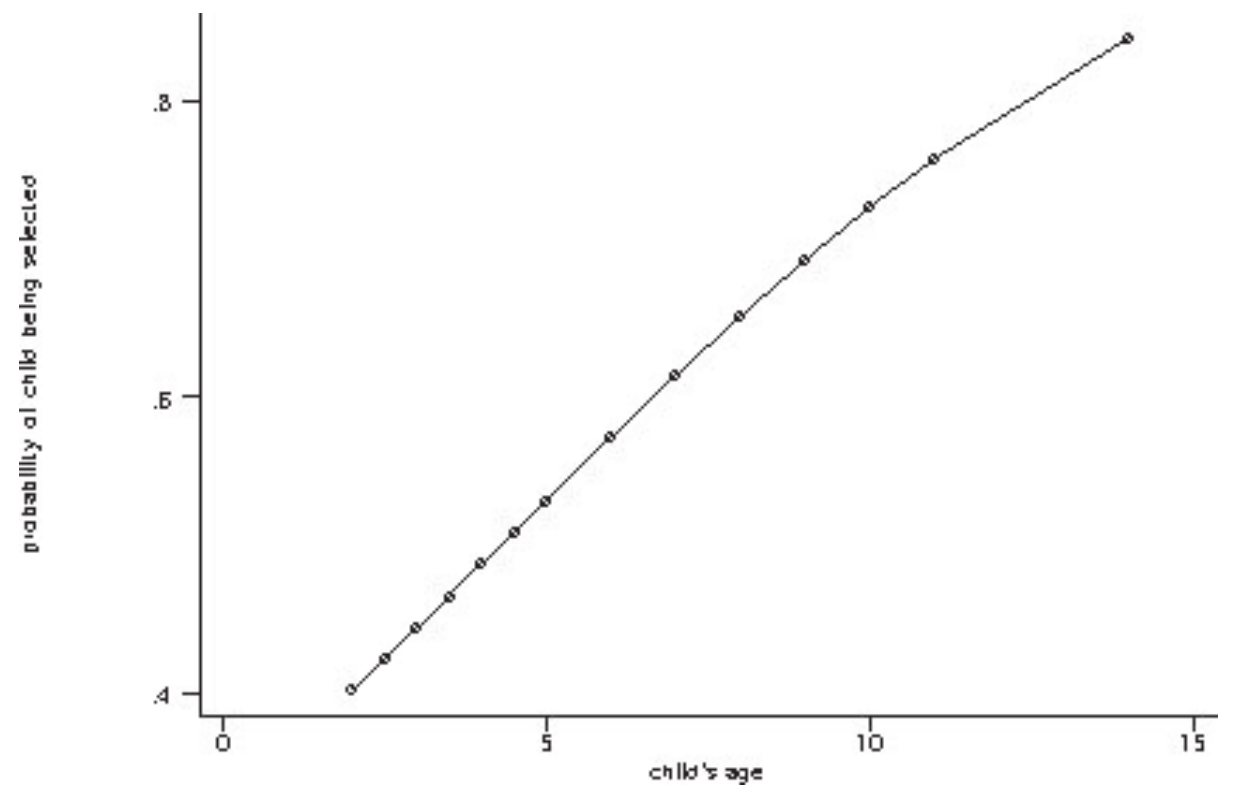

Figure 9. The relationship between doctors' selection and the child's age.

In order to evaluate the possible determinants of whom the physician selected, logistic regression was used in which the response variable was whether the child was selected to present his or her problem and the explanatory variables included the child's age, and the sex of the child, doctor, and parent. In this model, age significantly predicted physicians' selection practices. For each year of age the odds of the doctor selecting the child increased by 1.2 times $(z=2.376 ; p=0.018)$. The other explanatory variables were insignificant at the $p=0.05$ level. ${ }^{10}$ Figure 9 indicates the relationship between doctors' selection of the child and child's age:

In this graph the predicted probability of a child's being selected is plotted against the child's age. The upward pointing line indicates a strong positive relationship between the child's age and the likelihood that he or she will be selected by the physician to explain their problem.

\section{Consequences of Physicians' Selection Practices}

Each of the cases in these data was also coded for who presents the child's problem. Table 2 shows the tabulations of whom the doctor selects and who ultimately presents the problem. In this table we can see that when parents were selected to present, they did so a full 100\% of the time. By contrast, when children were selected, they presented the problem only $56 \%$ of the time, while parents present

${ }^{10}$ Goodness of fit for this logistic regression model was $\chi 2(46, N=102)=50.82, p=0.2894$ indicating a good fit of the model. 
Table 2. Frequency Distribution of Who Presents the Child's Problem

\begin{tabular}{lcccc} 
& & Problem presenter & & \\
Doctor selects & None & Parent & Child & Total \\
\hline Parent & 0 & 30 & 0 & 30 \\
Child & 2 & 22 & 30 & 54 \\
Ambiguous & 0 & 15 & 3 & 18 \\
Total & 2 & 67 & 33 & 102 \\
\hline
\end{tabular}

Pearson $\chi^{2}(4)=33.850 ; \operatorname{Pr}=0.000$

their problem $41 \%$ of the time. In two cases, neither the parent nor child presented the reason for visit. In these cases the physician reformulated the question as a candidate understanding of the problem. Parents also typically presented the problem when the physician was ambiguous in selecting a next speaker (83\%). In only three cases did children present their problem after a solicitation that did not unambiguously select them. Thus, whereas doctors select children more frequently than parents, their parents most frequently present the problem.

In order to evaluate what factors predict who presents the problem, I ran a second logistic regression. In this model, whether the child presented his/her problem or not was regressed on six explanatory variables: the child's age, whether or not the child was selected to present the problem, whether the child had been successfully engaged in a prior sequence of action, and the sex of the child, doctor, and parent. In this model, whether the child was selected to present the problem proved to be a very significant predictor. A child was 27 times more likely to present his or her problem if selected to do so than if he or she was not selected $(z=3.491 ; p<0.00)$. ${ }^{12}$ Additionally, whether the physician had engaged the child in talk prior to soliciting the problem significantly predicted whether the

${ }^{11}$ By a prior sequence of action, I am referring to adjacency pairs such as question-answer sequences and to such reciprocal actions as joke-laughter or shaking hands. When the doctor performed a first part action but the child did not respond, the sequence of action was incomplete for the purposes of this code. This variable was included because, according to Sacks et al. (1974), a bias may occur (as discussed earlier) in that if two parties are talking they may continue talking. Thus, if a doctor speaks to a child to, for example, asks his or her age and then asks about the problem, the child may be more likely to answer having been engaged already in the interaction. Going one step further, even if the two sequences were not adjacent, it is possible that simply having been engaged in a sequence of action the child would be more likely to participate in a second sequence of action even if several sequences of talk later. These more "distal" sequences were included in the analysis.

${ }^{12}$ Interaction effects with age and sex of the participants were also tested and proved insignificant at the 0.05 level. The regression included the use of a Huber correction for clustering by doctor to control for the effects of individual doctors on this communication practice. 


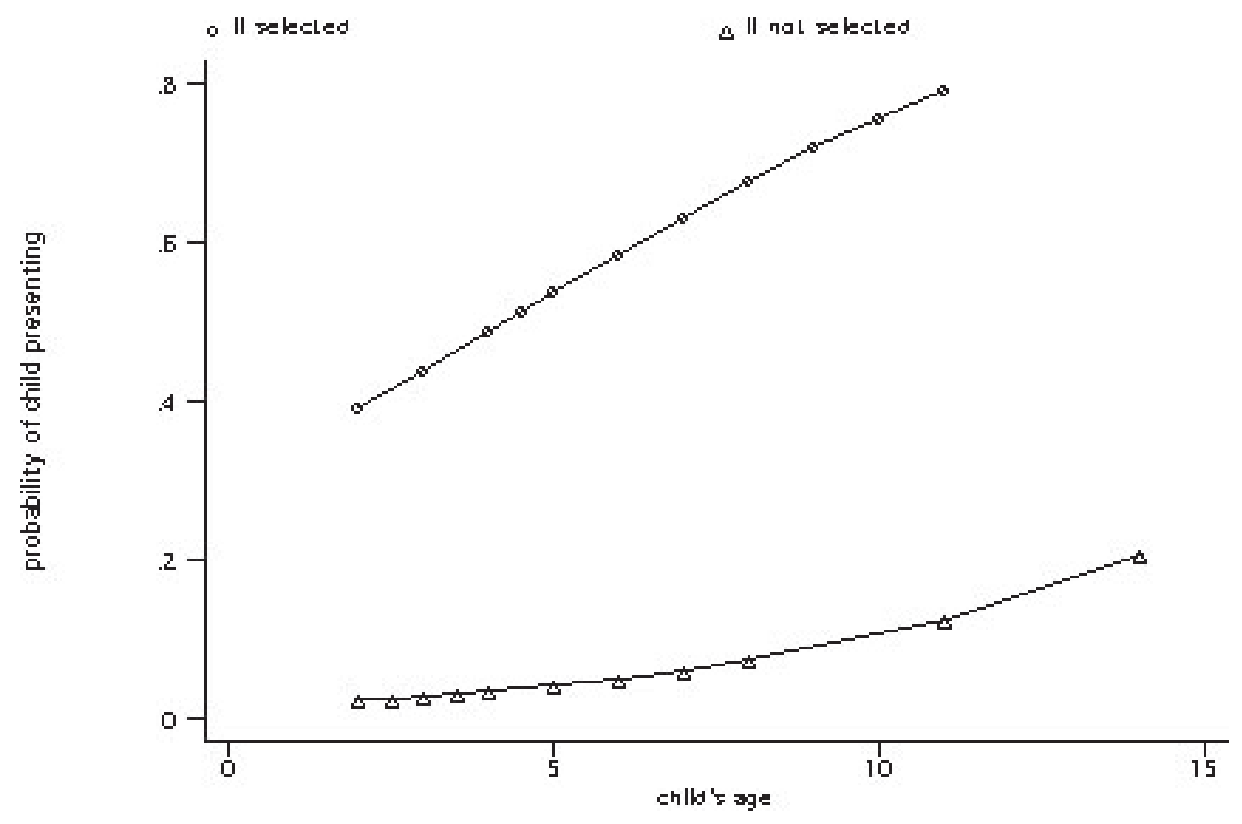

Figure 10. The relationship between children presenting their problem and their age.

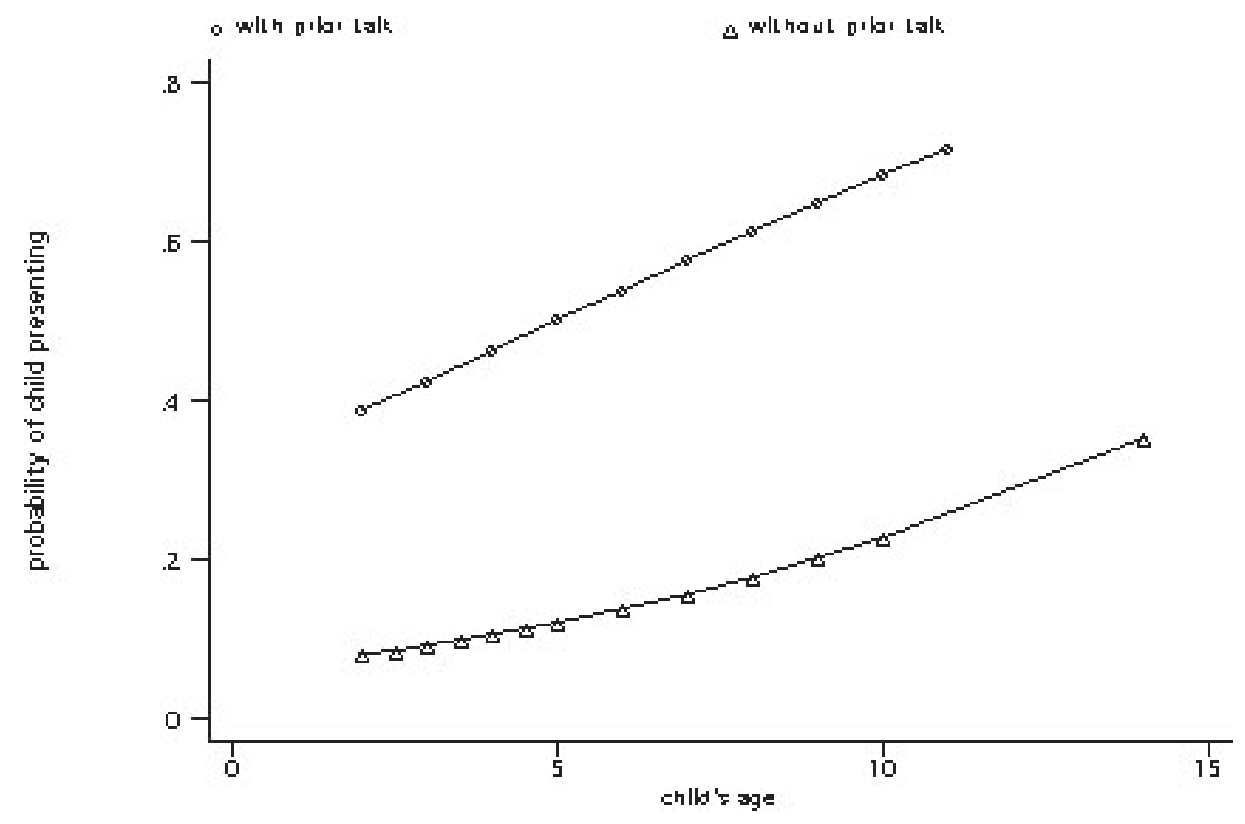

Figure 11. The relationship between the probability of chldren presenting their problems and their age with and without prior engagement (includes both selected and nonselected cases). 


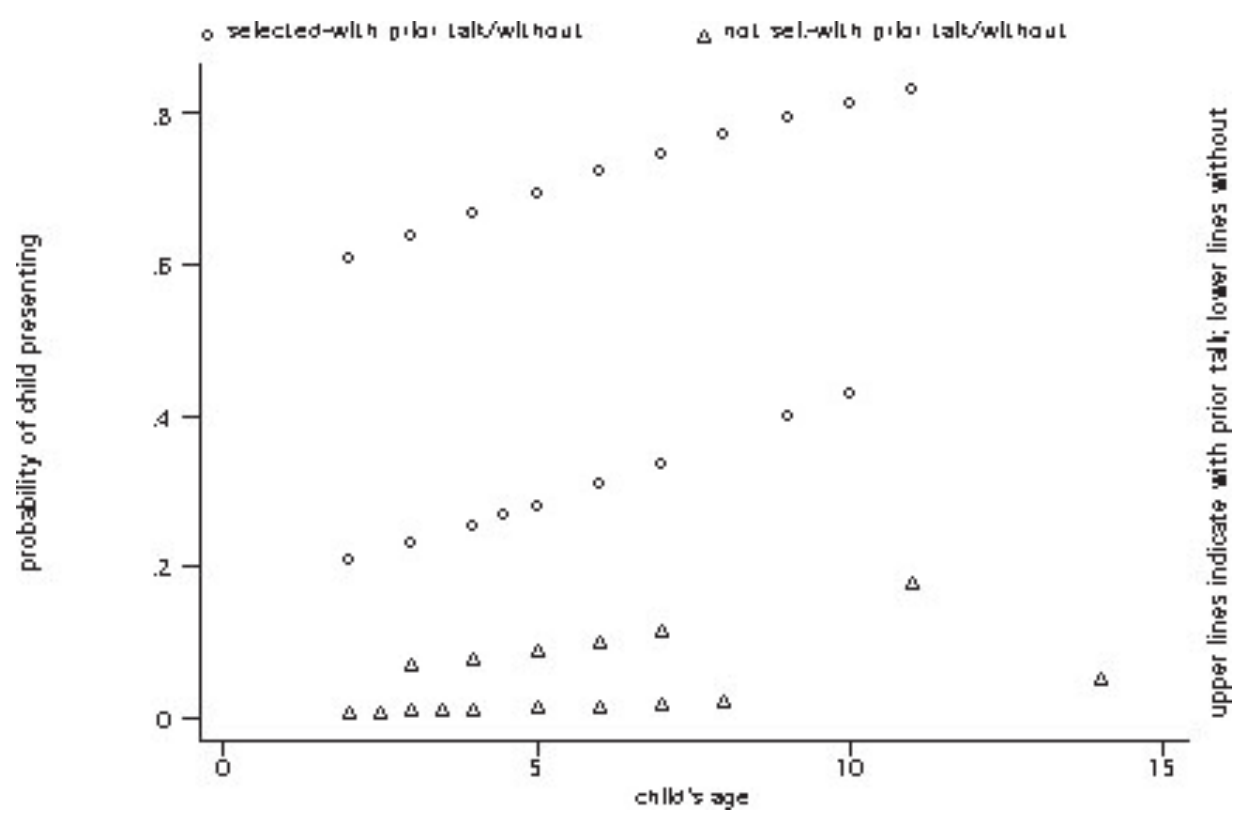

Figure 12. The relationship between the probability of children presenting their problems and their age, with and without selection and prior engagement.

child would present the problem. A child was seven times more likely to present their problem if he or she had been successfully engaged prior to the problem solicitation $(z=2.599 ; p=0.009)$. Although age indirectly affects this outcome through whether the child was selected, it does not have a significant direct effect in the model though there is a positive trend $(z=0.870 ; p=0.384)$. The relationship between whether the child presents, whether the child is selected, and the child's age can be seen in Figure 10, which shows that the age effect is manifested primarily in children who are selected to present.

In this graph the predicted probability of whether a child presented his or her problem was plotted against the child's age. The top line indicates that if the child is selected, regardless of age he or she will be significantly more likely to present his or her problem. The upward slope of each line indicates that regardless of whether they are selected to present the problem, as children grow older they are more likely to present their problem. As can also be seen in this graph, the line for children who have been selected is steeper, indicating a stronger relationship between whether the child presents and age when the child was selected to present the problem.

The relationship between prior engagement and whether a child presents is also very important. This is shown in Figure 11. Similar to the graph shown in Figure 10, here we can see that the likelihood that a child will present his or her problem increases with age; however, if the child is engaged in a sequence of 
action prior to the doctor's problem solicitation, this will increase the likelihood that the child will present. This is seen most clearly by the upper line, which begins at a much higher probability than its counterpart. When the practices of problem solicitation and prior engagement are taken together, we can see a marked difference in the likelihood that a child will present the problem (Figure 12).

The difference between each of the four roughly parallel lines indicates the difference in probability that both selection and prior talk make. The uppermost line shows that in these data children who are both engaged in the interaction prior to the problem solicitation and are selected by that solicitation are far more likely to present their problem (regardless of age) than children who are not selected or engaged. The lowermost line represents children who were neither engaged nor selected. The relative flatness of the line indicates that even as children grow older, if they are neither selected as next speaker nor engaged in prior talk, they are unlikely to present their problem.

\section{When Children Are Selected: Parent-Child Negotiation}

A majority of the time, as we saw in Table 1, doctors in these data ask children what their problem is, with age being an important predictor. Doctors selected children in 54 of 102 instances. Of these cases, the child presented his or her own problem in 30 instances, and the parent presented the problem in 22 instances. Given these figures, when the pediatrician selects the child, there is something going on within the interaction such that either the child or the parent may end up presenting the child's problem. This section explores this process.

In some cases when doctors ask children about the reason for the visit, they respond upon the doctor's turn completion and with a fully competent answer to their question (e.g., Extract 4). However, both in cases where the child ultimately does present his or her problem and in cases where the parent ultimately presents it, children are often less interactionally competent than their parents. They may be reluctant to speak even when selected or when they have been engaged in a prior sequence of action. In general, a child's reluctance will be manifested in the interaction with a silence. For example, in Extract 9, there is a 1.0 second silence in line 2 following the doctor's problem solicitation.

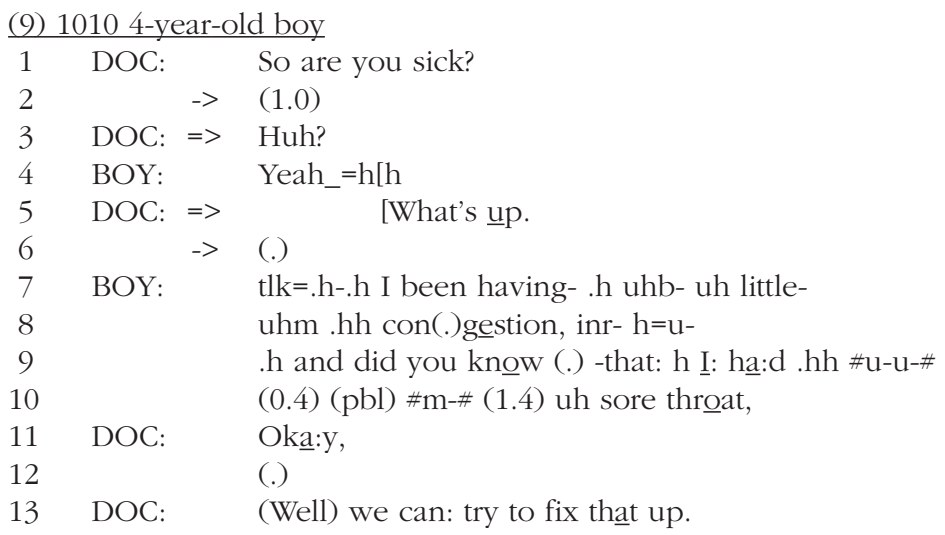


After the boy fails to respond in the 1.0 second silence (line 2), the doctor then pursues a response from the boy with a tag question "Huh?" in line 3 (Sacks et al., 1974). Following a simple, unelaborated answer from the boy, the doctor pursues a full problem presentation with a second question in line 5 ("What's upp."). Following the micropause the boy provides a problem presentation (lines 7-10). We do not have access to video for this case; however, the vocal behavior of the doctor and child, and the lack of vocal communication by the parent, all appear to orient to the boy's right and obligation to respond to the doctor's questions in lines 1 and 5. The doctor pursues a response from the boy, and the boy, in fact, does respond while the mother remains silent across this sequence. However, although the boy certainly does present his problem here, it is not immediately following the completion of the doctor's initial turn constructional unit. Rather, it is after multiple pursuits and delays. Thus, the fact that the boy comes to present his problem is an outcome that is interactionally achieved, the result of persistence by the doctor, forbearance by the parent, and collaboration by the child.

A similar outcome can be achieved in other ways. For example, in Extract 10, following a silence and an inadequate response, the mother not only withholds an adequate response but pursues an answer from the child on the doctor's behalf.

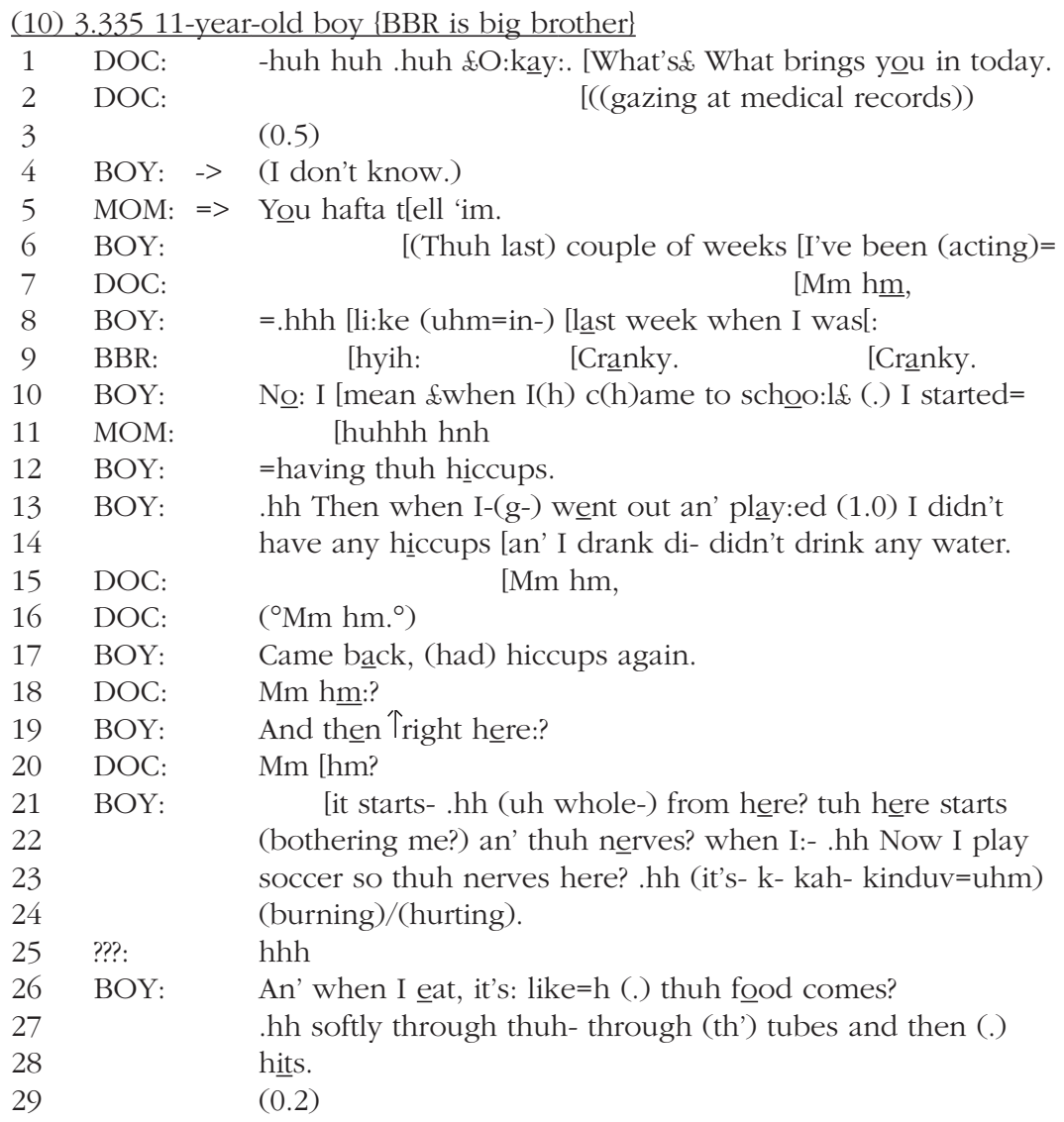




$\begin{array}{lll}30 & \text { BOY: } & \text { (hits me-) } \\ 31 & \text { MOM: } & \text { (It's jus- then he- }>\text { then he goes then 'e goes }<\text {.huhh-) } \\ 32 & & (0.5) \text { He feels- He says he feel (thuh [bump-) } \\ 33 & \text { DOC: } & \\ 34 & \text { BOY: } & \text { Yeah an' I feel pain right here right now. }\end{array}$

Here the doctor appears to select the child. He has just been talking with the child, and the additional stress on "you" appears to work to specify an otherwise ambiguous address term "you". Further, the boy does respond (line 3), although he does not initially provide an answer to the doctor's question. The mother shifts her gaze from the doctor to her son at the end of the problem solicitation. Her gaze supports her understanding that the boy is the appropriate respondent to the question. In response to the doctor's question, the boy first claims a lack of knowledge and therefore an inability to answer the question. However, in responding at all he also displays his understanding that he has a responsibility to respond to the question. A parent certainly could answer the doctor's question at that point, but following this, the mother gives a directive "You hafta tell 'im." Even before this turn is complete, though, the boy has begun the problem presentation. ${ }^{13}$ In this case we can again see that, in arriving at the actual presentation of the trouble, there is a negotiation among the doctor, parent, and child as to who will do the telling. Extracts 9 and 10 suggest that even in cases where the outcome is that the child responds, this outcome is the result of a process of interactional negotiation among the doctor, parent, and child.

Just as the outcome of children's presenting their problems is interactionally achieved, so too are outcomes when parents present on behalf of their children. In this corpus, when parents end up presenting their child's problem, this outcome is largely the result of interactional difficulties that the parent is attempting to alleviate. By interactional difficulties I mean that in one way or another the child does not respond to the solicitation adequately or in a timely fashion. ${ }^{14}$ of the 22 cases in which children were selected but parents presented, in only five of the cases did parents appear readily to present their child's problem at a point when the turn was rightfully the child's. Of the five cases, in three the doctor had been speaking with the parent prior to the solicitation, and the children had not been spoken to yet in the interaction. As shown in the earlier analysis, engaging the child significantly predicts whether they will present the problem. ${ }^{15}$ In one

${ }^{13}$ It appears that this "I don't know" was designed less as a complete response and more as a turn initial marker of uncertainty about the problem he is about to report-one that turns out to be rather amorphous, as can be seen across lines 6-34 (see Beach \& Metzger, 1997, for a discussion of claims of insufficient knowledge).

${ }^{14}$ Research on turn-taking has not yet fully explained the conditions in which nonselected recipients come to have turns in contexts such as this. However, these data indicate that nonselected recipients may take turns at talk but that typically they do so only in the face of, and in order to manage, interactional difficulties.

15 Further, it is possible that in this context a problem solicitation that selects the child is primarily marking off a shift to business-the child (e.g., So, Sadie, what's up?"). Because the child was not 
case the solicitation was ambiguous in whom it selected ("And you guys're both here today" said to the two children). Thus, there was only one case, for which there is no video, in which there is no apparent interactional explanation. In most cases, though, there was some form of interactional difficulty; the examples that follow are representative of these cases. For example, see Extract 11:

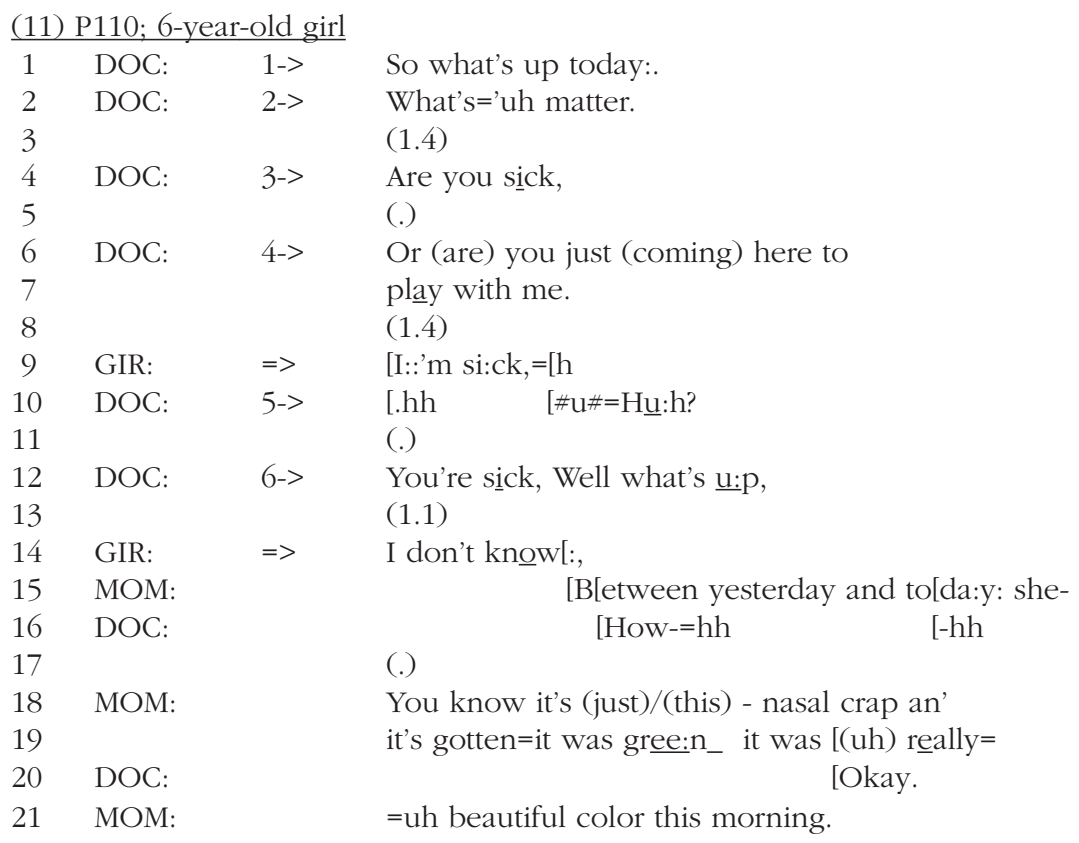

Although we do not have access to video for confirmation, the doctor's intonation across lines 1-2 has several characteristics of a child register indicating that these questions are directed to the child rather than the parent (Worobey et al., 1987). First, the pitch of these two units of talk is consistent with the pitch of earlier talk to the girl and is higher than talk to the parent just prior to this extract. Second, although "what's up" may be a general formulation, "What's='uh matter" seems specifically child-friendly as well as patient-directed rather than parentdirected because it is the girl who has something the matter. Though the doctor does not otherwise address the child, that the mother does not attempt to answer the questions in lines 1 or 2 even across the silence in line 3 further supports an orientation to the doctor's questions as selecting the girl rather than the mother.

In line 4 the doctor asks a third question, this time clearly addressed to and thus selecting the girl as next speaker. After a brief delay (line 5) the doctor provides a second component of the turn transforming a yes or no question into a choice of two alternatives. The girl responds by repeating the first alternative; however, when the doctor pursues this answer seeking additional information (lines 10 and 
12) the girl again delays and finally claims a lack of knowledge (line 14). It is only when the girl claims an inability to answer the question and thus an inability to present the problem that the mother self-selects and presents the girl's problem. In this case we can see even from the vocal behavior of the participants that there is an initial orientation to the child as the selected and responsible participant for providing the problem presentation. The negotiation in this extract is both between the doctor and child and between the parent and child.

Whereas Extract 9 would be coded as the child presenting, and Extract 11 would be coded as the parent presenting the problem, in both cases the participants can be seen to orient to the child's right to answer the question that selected him or her. That is, in both cases the parent does not attempt to respond to the doctor's problem solicitation right away or even upon observing interactional trouble (e.g., silence, pursuits of response). It is only after significant interactional difficulties that the parent orients to the possibility of presenting her child's problem.

Similar to Extract 11, in Extract 12 the doctor solicits the problem presentation from the girl in line 1. In overlap the mother begins something new, which is then abandoned. After 1.0 second of silence, the girl appears to respond. However, her utterance is unintelligible and appears to be treated that way by the physician as well, who subsequently begins to offer candidate understandings of the girl's problem.

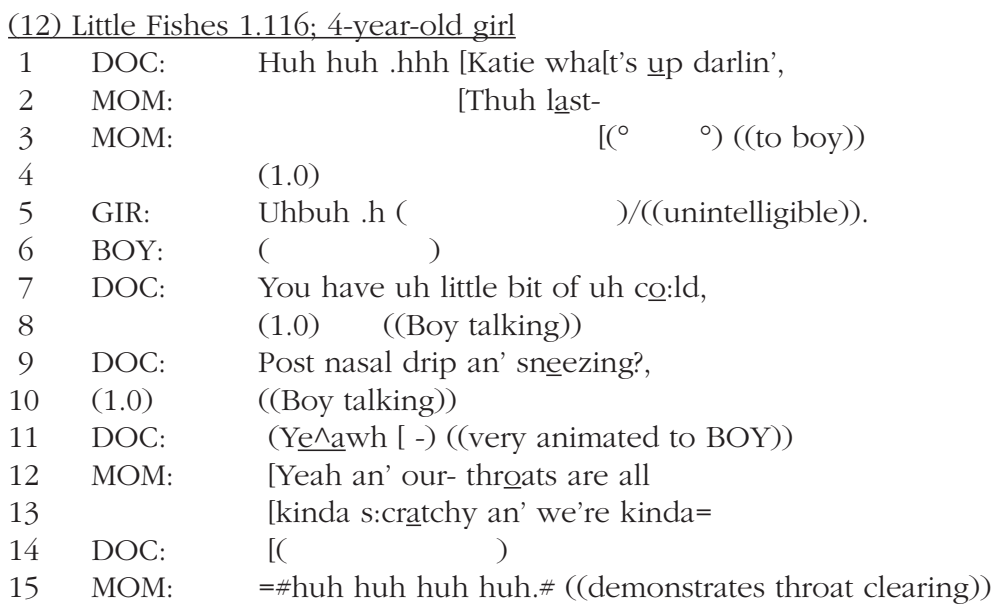

Neither of the doctor's candidate understandings (lines 7 and 9) are confirmed (or visibly attended to) by the girl, who is attempting to climb onto the examination table. It is only at this point that the mother offers a confirmation ("Yeah") and goes on to begin a problem presentation (lines 12-15). It is also noteworthy that even when the girl fails to present her problem in response to line 1, the doctor constructs her chart-based candidate understanding as addressing her through her use of "You." Further, her continuation in 9 is an expansion of "uh co:ld," and is done with the same voicing as line 7 , displaying her continued orientation to the child despite lexical choices that are likely much more understandable by this 4 year-old girl's mother than by her. 
In Extract (13) the doctor again solicits the problem presentation from the child. Here, the problem solicitation is done with a request for confirmation. However, in that the problem is vaguely stated ("some problem with your ey:e") and marked as not clearly understood ("or something"), the doctor clearly appears to be soliciting a presentation of the trouble (in a way that an unqualified request for confirmation would not necessarily do).

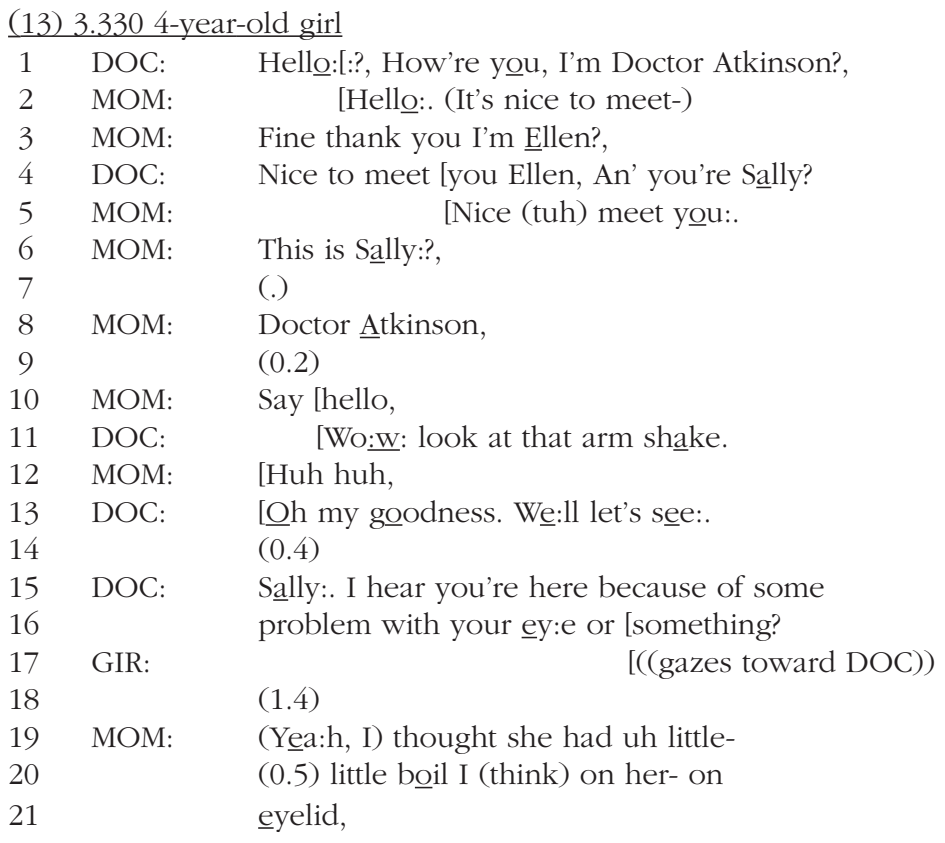

In line 6 the mother introduces her daughter, and they shake hands. The doctor shakes the girl's hand for an extended period of time adding the comment at line 11 as a joke to which the girl smiles in response. At line 15 the doctor addresses the girl with her name "Sally:" and then solicits a problem presentation. He selects the girl as next speaker through the use of the address term. However, the girl does not present her problem. She smiles and after a brief gaze toward the doctor, who is gazing at her chart, she looks down. During the 1.4 second silence her mother gazes toward her. The mother's gaze displays her orientation to the girl as the appropriate next speaker. When, after a relatively long silence, her daughter does not present her problem, the mother then proceeds to do so, first confirming the doctor's understanding and then presenting the problem ("uh little- (0.5) little boil I (think) on her- on eyelid,"). As with the other cases shown in this section, the doctor and parent display an orientation to the child as having the right and obligation to speak next. It is only when interactional difficulties arise (in this case a failure on the part of the child to respond to the doctor's problem solicitation in a timely fashion) that the parent responds on her child's behalf.

In this section I have discussed cases that might initially appear to support an argument that parents take their children's turns from them a significant propor- 
tion of the time (Extracts 11-13). In each of these cases, a child is selected but his or her parent ultimately presents the problem. I have argued here that, although this outcome is relatively common, upon closer examination of the process that leads up to it, what can be seen is that parents treat their children as having primary rights to respond when they have been selected as next speaker. Doctors and parents routinely work to allow children additional time to respond or to provide additional questions to which to respond. Parents seem oriented to a responsibility to provide an answer to the doctor's question, but if their child has been selected, this will be done only following interactional trouble as part of an effort to put the interaction "back on track."

\section{Discussion}

Researchers of pediatric interaction have noted children's relatively small level of participation in the encounter (e.g., Aronsson \& Rundström, 1988; Freemon et al., 1971; van Dulmen, 1998). However, as asserted by Tates and Meeuwesen, 2001), little research has attempted to explain the organization of that participation or to account for that organization (cf. Aronsson \& Rundström). Children's participation may vary, as suggested by Pantell et al. (1982), depending upon the activity (problem presentation versus treatment discussion). In this study I have focused on one particular activity in the encounter-one in which children are likely to have some participation. ${ }^{16}$ In exploring the solicitation and presentation of the reason for the visit in acute pediatric encounters, we have seen that the child's participation is the product of an interactional negotiation among the physician, the parent, and the child. In focusing entirely on the outcome (i.e., who eventually answers questions and provides information) researchers may miss the process that actually includes children and treats them as consequential parties in the interaction and may further miss the critical differences in participation across activities within the encounter.

This research supports the general finding discussed by Aronsson and Rundström (1988) that children can regularly end up not presenting their problem even in cases where they have been selected to do so. However, although Aronsson and Rundström found that "on average, the child would stand less than a 50\% chance of responding on his own to those turns which were, in fact, allocated to him" (p. 165), this study suggests that children are somewhat more likely to respond. Moreover, this study suggests that parents may not be as controlling as indicated by Aronsson and Rundström. In most of the cases, children were treated as having a right to answer a problem solicitation that selected them. Also, in most cases, parents did not attempt to provide an answer to the doctor's question until there had been substantial delay, multiple attempts to question the child, or inadequate answers by the child (Extracts 11-13). Parents also regularly hold their children accountable by prompting them to provide an answer (e.g., Extract 10).

${ }^{16}$ Children, particularly very young children, would be less expected to participate substantively in discussions of diagnosis and treatment. 
These data indicate that parents will perform second pair part actions (e.g., answering questions that selected the child as next speaker) only when the child has displayed an inability to answer the question or the interaction otherwise has encountered difficulty. Although these data would support the argument that some parents will refrain from answering a question longer than other parents (e.g., allowing the doctor to pursue a given line of questioning for multiple rounds as opposed to just one), ${ }^{17}$ they also indicate that this is a second-order process in terms of explaining the child's participation. That is, before assertions of interactional dominance or asymmetry can be made, an investigation of the practices for speaker selection must be understood. We have seen that first and foremost the child's participation is the result of doctors' selection practices and parents' and children's use of gaze, gesture, and silence to negotiate who will perform the action of problem presentation. Additionally, we have seen that parents orient to children as having a right to present their own trouble when they are selected as next speaker as well as when the next speaker selection is ambiguous.

This study suggests that children's own actions are consequential for their participation as well, and that when they decline to talk, pass the floor to their parents, or display a lack of knowledge, parents then may present the problem on their behalf. Although the medical training literature suggests that doctors solicit information from children whenever possible, doctors may need a more clear understanding of what interactional barriers exist to children answering their questions.

The primary finding of this study is that, though parents most often present their children's problems, interactional resources such as selecting the child and engaging the child in talk prior to the solicitation can be used if the pediatrician wants to increase the chances that the child will explain his or her reason for visiting. In several of the extracts shown here the doctors asked the children how old they were, about upcoming birthdays or holidays, or about school. This talk also may allow the doctor to assess the child's level of interactional competence to determine whether the child likely will be able to provide an answer to a problem solicitation.

Pediatricians, as well as other health professionals who deal with multiple parties, could benefit from an understanding of the ramifications of their selection practices. Regularly, doctors develop a standard opening question that they use much of the time when dealing with acute encounters. If this opening question selects the parent as next speaker (e.g., "What's the trouble with Alex today") this makes it specifically relevant for the parent to present the trouble and makes it very difficult for the child to participate in that activity. Although cases where physicians begin with a history-taking question such as "How long has she had the fever?" were not analyzed here, such a question-especially insofar as it initiates a line of history-taking questions that may be increasingly outside of the child's domain of knowledge-may even further exclude the child from participating in the activity of establishing the reason for the visit. In fact, such an opening may make it difficult for the child to participate until the physical examination is initiated.

${ }^{17}$ Aronsson \& Rudström (1988) differentiated these as high and low control parents. 
Finally, as medical textbooks have suggested, children's participation in the pediatric encounter can be quite valuable. As indicated in Table 1, doctors appear to be most interested in hearing the problem from the child; this is the party most frequently selected by physicians to present their problem. The child's inclusion in the medical encounter is important not only for purposes of health care but also for purposes of socialization. Children's medical visits likely will shape their health beliefs, and their participation in the visit likely will be consequential for how they understand the role of medicine in their lives. Although children come to the doctor under the guardianship of a caregiver, they are nonetheless the owners of their own experiences and in this way have primary rights, especially as they grow older, to report their own illness experience (see Sacks, 1992, pp. 242-243, re: storytelling). A pediatrician's encouragement of this activity may help to generate an early sense of personal efficacy in terms of the child's health care. Although we can only speculate, it seems that patients who have been socialized throughout their childhood to take part in their medical encounters and in their health care will enter adult patienthood as more responsible and proactive patients.

\section{Appendix A: Transcript Symbols}

1. Temporal and sequential relationships

A. Overlapping or simultaneous talk is indicated in a variety of ways.

[ Separate left square brackets, one above the other on two successive

[ lines with utterances by different speakers, indicates a point of overlap onset, whether at the start of an utterance or later.

] Separate right square brackets, one above the other on two successive

] lines with utterances by different speakers indicates a point at which two overlapping utterances both end, where one ends while the other continues, or simultaneous moments in overlaps which continue.

$=\quad$ B. Equal signs ordinarily come in pairs - one at the end of a line and another at the start of the next line or one shortly thereafter. They are used to indicate two things:

1) If the two lines connected by the equal signs are by the same speaker, then there was a single, continuous utterance with no break or pause that was broken up in order to accommodate the placement of overlapping talk.

2) If the lines connected by two equal signs are by different speakers, then the second followed the first with no discernible silence between them, or was "latched" to it.

(0.5) C. Numbers in parentheses indicate silence, represented in tenths of a second; what is given here in the left margin indicates 5/10 seconds of silence. Silences may be marked either within an utterance or between utterances. 
(.) D. A dot in parentheses indicates a "micropause," hearable but not readily measurable; ordinarily less than $2 / 10$ of a second.

2. Aspects of speech delivery, including aspects of intonation.

A. The punctuation marks are not used grammatically, but to indicate

? intonation. The period indicates a falling, or final, intonation contour, not necessarily the end of a sentence. Similarly, a question mark indicates rising intonation, not necessarily a question, and a comma indicates

? " continuing," intonation, not necessarily a clause boundary. A combined question mark and comma indicates a rise stronger than a comma

- $\quad$ but weaker than a question mark. An underscore following a unit of talk indicates level intonation.

: : $\quad$ B. Colons are used to indicate the prolongation or stretching of the sound just preceding them. The more colons, the longer the stretching.

- $\quad$ C. A hyphen after a word or part of a word indicates a cut-off or self-interruption.

word D. Underlining is used to indicate some form of stress or emphasis, either by increased loudness or higher pitch. The more underlining, the greater the emphasis.

E. The degree sign indicates that the talk following it was markedly quiet or soft. When there are two degree signs, the talk beween them is markedly softer than the talk around it.

$\wedge \quad$ G. The carrot indicates a rise in pitch.

$>\quad$ H. The combination of "more than" and "less than" symbols indicates that the talk between them is compressed or rushed. Used in the reverse order,

$<\quad$ they can indicate that a stretch of talk is markedly slowed or drawn out. The "less than" symbol by itself indicates that the immediately following talk is

$<\quad$ "jump-started," that is, sounds like it starts with a rush.

hhh I. Hearable aspiration is shown where it occurs in the talk by the letter "h" the more $h s$, the more aspiration. The aspiration may represent breathing,

(hh) laughter, and so on. If it occurs inside the boundaries of a word, it may be enclosed in parentheses in order to set it apart from the sounds of the word.

.hh If the aspiration is an inhalation, it is shown with a dot before it.

3. Other markings.

(( )) A. Double parentheses are used to mark transcriber's descriptions of events, rather than representations of them. Thus ((cough)), ((sniff)), ((telephone rings $)),(($ footsteps $)),(($ whispered $)),(($ pause $))$, and the like. 
(he) B. When all or part of an utterance is in parentheses, or the speaker identification is, this indicates uncertainty on the transcriber's part, but represents a likely possibility.

( ) Empty parentheses indicate that something is being said, but no hearing (or, in some cases, speaker identification) can be achieved.

\section{References}

Aronsson, K., \& Rundström, B. (1988). Child discourse and parental control in pediatric consultations. Text 8(3), 159-189.

Athreya, B. H., \& Silverman, B. K. (1985). Pediatric physical diagnosis. Norwalk, CT: Appleton-Century-Crofts.

Bates, B., Bickley, L. S., \& Hoekelman, R. A. (1995). Physical examination and history taking (6th ed.). Philadelphia: Lippincott.

Bates, E., Dale, P., \& Thal, D. (1995). Individual differences and their implications for theories of language development. In P. Fletcher \& B. MacWhinney (Eds.), The handbook of child language (pp. 96-151). Oxford, UK: Blackwell.

Beach, W. A. (1995). Preserving and constraining options: "okays" and "official" priorities in medical interviews. In B. Morris \& R. Chenail (Eds.), Talk of the clinic: Explorations in the analysis of medical and therapeutic discourse. Hillsdale NJ: Erlbaum.

Beach, W. A. (2001). Revealing moments: Formulating understandings of adverse experiences in a health appraisal interview. Social Science and Medicine, 52(1), 25-44.

Beach, W. A., \& Metzger, T. R. (1997). Claiming insufficient knowledge. Human Communication Research, 23(4), 562-588.

Beckman, H., \& Frankel, R. (1984). The effect of physician behavior on the collection of data. Annals of Internal Medicine, 101, 692-696.

Drew, P., \& Heritage, J. (1992). Analyzing talk at work: An introduction. In P. Drew \& J. Heritage (Eds.), Talk at work (pp. 3-65). Cambridge, UK: Cambridge University Press.

Freemon, B., Negrete, V., Davis, M., \& Korsch, B. (1971). Gaps in doctor-patient communication: Doctor-patient interaction analysis. Pediatric Research, 5, 298-311.

Goodwin, C. (1981). Conversational organization: Interaction between speakers and hearers. New York: Academic Press.

Goodwin, M. H., \& Goodwin, C. (1986). Gesture and coparticipation in the activity of searching for a word. Semiotica, 62, (1/2), 51-75.

Heath, C. (1981). The opening sequence in doctor-patient interaction. In P. Atkinson \& C. Heath (Eds.), Medical work: Realities and routines (pp. 71-90). Aldershot, UK: Gower.

Heritage, J. (1984). Garfinkel and ethnomethodology. Cambridge, UK: Polity Press.

Heritage, J. (in press). Accounting for the visit: Giving reasons for seeking medical care. In J. Heritage \& D. Maynard (Eds.), Practicing medicine: Talk and action in primary-care encounters. Cambridge, UK. Cambridge University Press.

Korsch, B., Gozzi, E. K., \& Francis, V. (1968). Gaps in doctor-patient communication. Pediatrics 42, $855-871$.

Labov, W., \& Fanshel, D. (1977). Therapeutic discourse: Psychotherapy as conversation. New York: Academic Press. 
Lerner, G. (1993). Collectivities in action: Establishing the relevance of conjoined participation in conversation. Text 13(2), 213-245.

Lerner, G. (in press). Some "context-sensitive" methods for selecting next speaker. Language in Society.

Lipkin, M., Frankel, R., Beckman, H., Charon, R., \& Fein, O. (1995). Performing the interview. In M. Lipkin, S. Putnam, \& A. Lazare (Eds.), The medical interview: Clinical care, education, and research (pp. 65-82). New York: Springer Verlag.

Ochs, E., \& Schieffelin, B. (1984). Language acquisition and socialization: Three developmental stories and their implications. In R. Shweder \& R. Levine (Eds.), Culture theory: Essays on mind, self and emotion (pp. 276-320). New York: Cambridge University Press.

Pantell, R. H., Stewart, T., Dias, J., Wells, P., \& Ross, A. W. (1982). Physician communication with children and parents. Pediatrics, 70(3), 396-402.

Robinson, J. D. (1998). Getting down to business: Talk, gaze, and body orientation during openings of doctor-patient consultations. Human Communication Research, 25(1), 97-123.

Robinson, J. D. (in press). Generating patients' presenting concerns. In J. Heritage \& D. Maynard (Eds.), Practicing medicine: Talk and action in primary-care encounters. Cambridge, UK: Cambridge University Press.

Sacks, H. (1984). On doing "being ordinary." In J. M. Atkinson \& J. Heritage (Eds.), Structures of social action (pp. 413-429). Cambridge, UK: Cambridge University Press.

Sacks, H. (1992). Lectures on conversation, vol. 2 (Fall 1968-Spring 1972), pp. 242-243. Oxford, UK: Blackwell.

Sacks, H., Schegloff, E. A., \& Jefferson, G. (1974). A simplest systematics for the organization of turntaking for conversation. Language, 50, 696-735.

Schegloff, E. A. (1995). Parties and talking together: Two ways in which numbers are significant for talk-in-interaction. In P. Ten Have \& G. Psathas (Eds.), Situated order: Studies in social organization and embodied activities (pp. 31-42). Washington, DC: University Press of America.

Schegloff, E. A. (1996). Turn organization: One intersection of grammar and interaction. In E. Ochs, S. Thompson, \& E. Schegloff (Eds.), Interaction and grammar (pp 52-133). Cambridge, UK: Cambridge University Press.

Schegloff, E. A. (2000). Overlapping talk and the organization of turn-taking for conversation. Language in Society, 29(1), 1-63.

Schegloff, E. A., \& Sacks, H. (1973). Opening up closings. Semiotica, 8, 289-327.

Seidel, H. M., Ball, J. W., Dains, J. E., \& Benedict, G. W. (1995). Mosby's guide to physical examination (3rd ed.). New York: Mosby.

Simmel, G. (1950). The sociology of Georg Simmel. (Kurt Wolff, Trans.). Glencoe, IL: Free Press.

Tannen, D., \& Wallat, C. (1986). Medical professionals and parents: A linguistic analysis of communication across contexts. Language in Society, 15, 295-312.

Tannen, D., \& Wallat, C. (1987). Interactive frames and knowledge schemas in interaction: Examples from a medical examination/interview. Social Psychology Quarterly, 50, 205-216.

Tates, K., \& Meeuwesen, L. (2001). Doctor-patient-child communicaton. A (re)view of the literature. Social Science E Medicine, 52, 839-851.

van Dulmen, A. M. (1998). Children's contributions to pediatric outpatient encounters. Pediatrics, $102(3$ Pt 1), 563-568.

Worobey, J. H., O'Hair, D., \& O'Hair M. J. (1987). Pediatrician-patient-parent communications: A descriptive analysis. Language and Communication, 7(4), 293-301. 